\title{
Recontextualização do currículo integrado na formação médica
}

\author{
Marcia Regina Selpa Heinzle* , Maria Helena Salgado Bagnato* *
}

http://dx.doi.org/10.1590/0103-7307201507811

\section{Resumo}

Este artigo analisa as propostas de currículo integrado de duas escolas médicas de Santa Catarina com o propósito de compreender o processo de recontextualização do currículo integrado mediante a teoria do Dispositivo pedagógico de Basil Bernstein, mais precisamente os conceitos de recontextualização. A partir de questões norteadoras que envolveram a pesquisa, foi possível identificar as ambivalências das motivações e as influências das políticas no campo da recontextualização oficial, assim como os sentidos da integração curricular no campo pedagógico. Constatou-se que tais concepções, influências e motivações são recontextualizadas e reinterpretadas nos diferentes contextos em função da história de vida pessoal e profissional de cada ator social e das complexas conexões com a coletividade, a cultura e as relações de poder.

Palavras-chave: currículo integrado, formação médica, recontextualização
* Universidade Regional de Blumenau- FURB. Programa de Pós-Graduação Mestrado em Educação. Grupo de Estudos e Pesquisas em Educação SuperiorGEPES/FURB: Blumenau, Santa Catarina, Brasil. selpamarcia@gmail.com

** Universidade Estadual de Campinas - Unicamp, Faculdade de Educação, Departamento de Ensino e Práticas Culturais; Campinas, São Paulo, Brasil. mhbagnato@gmail.com 


\title{
The process of recontextualizing the integrated curriculum in medical education
}

\begin{abstract}
This article analyzes the integrated-curriculum proposals of two medical schools located in the state of Santa Catarina, Brazil, in order to understand the re-contextualization process they underwent as understood by Basil Bernstein in his theory of the Pedagogic Device. The results show the ambivalences of motivations and the influence of policies in the official field, as well as the meanings of curriculum integration in the educational field. The article shows that such influences and motivations are re-contextualized and re-interpreted in different contexts accordingly to the personal and professional history of each social actor and the complex connections they establish with the collectivity, the culture and the power relations.
\end{abstract}

Keywords: integrated curriculum, medical education, recontextualization 


\section{Introdução}

Esta pesquisa foi delineada num contexto de reivindicações de mudanças curriculares na área da saúde. 0 desafio proposto foi o de reconhecer o processo de construção e recontextualização do currículo integrado dos cursos de medicina da Universidade Federal de Santa Catarina - UFSC - e da Universidade Comunitária Regional de Chapecó - Unochapecó. Vale ressaltar que a pesquisa não teve a intenção de comparar as propostas pedagógicas dos dois cursos, tampouco de analisar quais currículos estavam mais integrados. A pesquisa buscou compreender: qual o sentido da integração curricular nas propostas pedagógicas dos cursos de medicina; quais as principais motivações e influências que envolveram estas propostas curriculares; que ressignificações ocorreram no processo de construção das propostas de currículo integrado.

Com o objetivo de investigar essas questões, optou-se pela entrevista semiestruturada, que, a partir do roteiro guia, possibilitou aos entrevistados discorrer sobre o tema em estudo e, de certa forma, processar narrativas de suas trajetórias durante o processo de construção da proposta curricular. Assim, buscou-se a interlocução com diferentes docentes protagonistas da implantação da proposta curricular que revelaram contextos, influências, concepções e práticas sobre um currículo integrado nas duas diferentes instituições de ensino. Outro instrumento de recolha de dados foi a análise dos projetos pedagógicos dos cursos em questão, buscando identificar os elementos constitutivos da proposta de currículo integrado.

Partiu-se do pressuposto de que o currículo é um processo político, um artefato social e histórico; é resultado de circularidade de textos e discursos. Desse modo, a construção política e social do currículo é expressão de princípios e teorias de um determinado tempo histórico. Portanto, compreender o pensamento curricular e a gênese das organizações curriculares implica em resgatar a sua trajetória historicamente construída e as múltiplas leituras e interpretações que se estabelecem.

Na concepção de Goodson (1995), é preciso “entender a forma como o currículo é atualmente produzido e por que os assuntos operam deste e não de outro modo. Em síntese, necessita-se de uma teoria de contexto que justifique a ação” (p. 63), no sentido de abranger a prática, ou, em outras palavras, uma teoria sobre como se origina o currículo existente, como ele é reproduzido.

Em relação ao modelo predominante de organização curricular disciplinar, de acordo com Torres Santomé (1998), trata-se de uma estruturação que, historicamente, esteve vinculada à transformação social. Um dos adventos foi a expansão da in- 
dustrialização, que demandou um novo perfil de cidadão/trabalhador, necessitando assim, de uma formação cada vez mais especializada. As posições políticas e as instituições formadoras, por sua vez, produziram currículos na perspectiva do perfil encomendado, revelador de uma ideia de homem e de uma sociedade concebida como funcionalista e universal.

Basil Bernstein (1996) salienta que, numa organização curricular disciplinar, denominada por ele como "currículo coleção", as áreas e os campos de conhecimento são mantidos fortemente isolados e separados, o que caracteriza sua forte classificação. Os efeitos dessa concepção de currículo evidenciam o caráter normativo nas instituições de ensino, a partir da denominação, e a caracterização das aulas compartimentadas, por meio de facções dos conteúdos, dos horários, das grades, entre outros padrões.

Esta pesquisa nos dá a dimensão da complexidade do processo de superação do modelo disciplinar, ao propor currículos integrados. Nesse conflito entre as duas perspectivas, Lopes (2008) contribui, ao fazer uma distinção entre currículo disciplinar e currículo integrado.

0 currículo disciplinar é entendido como consequência de princípios de organização curricular baseados na lógica das ciências ou na natureza do conhecimento, enquanto currículos integrados são entendidos como algo baseado nos interesses e necessidades dos alunos e na relevância social do conhecimento (p.43).

A autora defende que há, no currículo integrado, uma diversidade de fundamentações e matrizes diferenciadas, porém, o princípio integrador circunscreve-se na "valorização das experiências e da vivência dos alunos" (p. 80).

Bernstein (1981) corrobora essa ideia, definindo essa organização curricular de “código integrado" e retrata que, nessa organização, as distinções entre as diferentes áreas de conhecimento são menos nítidas, muito menos marcadas, pelo fato de haver inter-relações do conhecimento. Dentre esses conceitos, Lopes (1999) esclarece que Bernstein parece crer nas inúmeras vantagens dos currículos em código integrado.

Estes seriam capazes de, a partir do abrandamento dos enquadramentos e das classificações, conferir maior iniciativa aos professores e alunos, maior integração dos saberes escolares com os saberes cotidianos dos alunos, de maneira a combater a visão hierárquica e dogmática do conhecimento. Em suma, a modificação na estrutura do 
conhecimento escolar alteraria relações de poder na escola, com implicações sociais nítidas (Lopes, 1999, p.188).

A proposta de currículo integrado na Educação Superior desafia os atores sociais a rever: as concepções do processo ensino aprendizagem; o perfil de formação profissional; a lógica da organização dos componentes curriculares; as práticas metodológicas e avaliativas; e ainda as relações de coletividade da docência que os atores sociais estabelecem nesse processo.

Ratificam-se as constatações de Feuerwerker (2002), ao afirmar que, no caso da formação médica, essas mudanças curriculares são profundas, pois, “implicam a transformação não somente de concepções e práticas, mas também de relação de poder dentro das universidades, dos serviços de saúde, do território local, e também no espaço social, no campo das políticas" (p.288).

No caso das propostas pedagógicas analisadas, esses elementos estão explicitamente presentes. As respostas às questões norteadoras apresentaram relatos enriquecedores de histórias de vida dos atores entrevistados nesse contexto de mudanças. Também revelaram suas influências, motivações e expectativas em transformar o ensino médico. Essas narrativas levam a refletir sobre o fato de os sujeitos sociais fazerem emergir da associação do contexto coletivo com o individual, significados de expressão social.

Entende-se, neste estudo, que o processo de construção de um currículo é resultado de intenções políticas, de escolhas, seleções, princípios e concepções produzidas e recontextualizadas. Para tanto, buscou-se a teoria do Dispositivo pedagógico, de Basil Bernstein (1996), a partir das regras de recontextualização, para compreender melhor nossas indagações.

\section{Os campos de recontextualização oficial e pedagógico}

Uma das contribuições teóricas na análise da geração de dados nesta pesquisa foi o enfoque da teoria do Dispositivo Pedagógico de Bernstein (1996), mais precisamente as regras de recontextualização, que atuam no campoํㅜ oficial e no campo pedagógico. Essas regras regulam a comunicação pedagógica, criando um regulador simbólico da consciência e, através dos meios discursivos, estabelecem suas próprias representações ideológicas. Para Bernstein (1996), a comunicação linguística simboliza a identidade social, afirmando

1. 0 termo campo é compreendido por Bernstein a partir do conceito de Bourdieu (2000), que pode ser considerado tanto um campo de força, quanto um campo de lutas, no qual os agentes atuam de acordo com suas posições, mantendo ou modificando sua estrutura. 
que, "sempre que um discurso se move, há espaço para a ideologia atuar" (p. 24).

Bernstein (1996) revela a evolução do desenvolvimento do conceito de códigos sociais e educativos e suas implicações para a reprodução social. A teoria dos códigos enfatiza as relações de poder e as práticas de transmissão, aquisição e avaliação que acontecem no interior da instituição. Reforça a ideia de que o currículo não se restringe ao contexto da sala de aula, ocupa tempos e espaços guiados por questões sociológicas, epistemológicas e políticas. Está implicado em relações de poder. According to Bernstein in Class, Codes and Control (1971)

Na teoria do Dispositivo Pedagógico, Bernstein (2003) distingue que o Campo Recontextualizador Oficial (CRO) é o campo da elaboração e da implementação das políticas educativas, dominadas pelo Estado e suas agências especializadas, sob influência do campo internacional, em produzir o Discurso Pedagógico Oficial (DPO). Conceitua ainda que os Campos Oficiais de Recontextualização "são arenas para a construção, distribuição, reprodução e mudança de identidades pedagógicas” (p.80).

O Campo de Recontextualização Pedagógica (CRP) trata do que é constituído por profissionais e pesquisadores da educação, de universidades, escolas e outras instituições. Mainardes e Stremel (2010) afirmam que, “igualmente ao CRO, o CRP preocupa-se com os princípios e práticas que regulam o movimento dos discursos do contexto da produção para o contexto de sua reprodução” (p. 13). Assim, tanto o Campo de Recontextualização Oficial quanto o Campo de Recontextualização Pedagógica são influenciados pelas relações de poder e disputam espaços e influências na configuração do discurso e da prática pedagógica. Concordamos com Mainardes e Stremel (2010), quando esclarecem que "o conceito de recontextualização tem contribuído significativamente para compreender, dentro do campo das políticas educacionais, como estas são recebidas ou emprestadas de outros contextos e recontextualizadas de acordo com as arquiteturas nacionais (constituídas por aspectos políticos, ideológicos e culturais)" (p. 21).

Após a compreensão desses conceitos, fez-se necessário investigar, no Campo de Recontextualização Oficial (CRO), quais foram as principais políticas e os programas de incentivo às mudanças curriculares na área da saúde e quais delas exerceram maior influência na construção do currículo integrado destes cursos de medicina.

Nesta análise, foram consideradas as vozes de dez sujeitos entrevistados, entre eles, dois coordenadores dos cursos de medicina, citados no início do trabalho, e demais docentes com distintas áreas de formação, a saber: pediatria, saúde coletiva, clínica cirúrgica, oncologia, imunologia e fisiologia. 


\section{A recontextualização do currículo integrado no campo oficial}

São destacadas, a seguir, as influências no campo oficial, em âmbito internacional e nacional, mencionadas pelos atores sociais no processo de construção e implementação do currículo integrado nas duas escolas médicas investigadas.

a) Influências internacionais

As diversas políticas vinculadas aos movimentos internacionais mencionados pelos entrevistados demarcam expressivamente perspectivas de melhorias das condições de saúde, mudanças na formação do perfil dos profissionais médicos, bem como estímulo às políticas de expansão das vagas nas escolas médicas. De acordo com Perim (2007),

o movimento internacional, especialmente na América Latina, impulsionava as reformas à medida que cada vez mais buscava a interação entre academia e serviços e a formação de profissionais preparados para enfrentar os problemas relacionados às necessidades sociais da população, exigindo mais do que capacidade técnico-científica (p. 94).

Entre as políticas e os movimentos foram citados: a primeira agência da Organização Pan-Americana da Saúde - OPAS; as pesquisas que culminaram com o Relatório Flexner; as Fundações Rockefeller e a Kellogg; as propostas curriculares das universidades de McMaster no Canadá e em Maastricht, na Holanda, que desenvolveram um currículo denominado Problem-based Learning - PBL; e as conferências internacionais sobre promoção da saúde e discussões sobre a formação médica.

É possível reconhecer, pelos dizeres dos entrevistados, que esses, dentre outros movimentos internacionais, contribuíram na difusão da necessidade de mudança na formação médica dos currículos analisados. Entretanto, nessas influências há um universo de ressignificações que se manifestou por multiplicidades de interpretações, posições e decisões ideológicas. Essas manifestações estão mais nítidas nas vozes dos professores do curso de medicina da UFSC, pois a criação do curso remonta aos anos de 1960, período em que muitos docentes vivenciaram as discussões desses movimentos históricos.

Dessa forma, é possível dizer que o discurso oficial pode ser reinterpretado e ressignificado baseado em diferentes experiências, concepções e contextos nos quais os sujeitos sociais estão inseridos.

b) as influências nacionais

A partir das sucessivas críticas ao profissional médico, tanto no campo das práti- 
cas em saúde como no plano epistemológico da formação médica, outras influências estiveram presentes no contexto das mudanças, como, por exemplo, o movimento da Medicina Integral e Preventiva, que caracterizou os anos de 1950 e que enfatizava o indivíduo na sua totalidade biopsicossocial. A partir desse movimento passaram-se a integrar nos currículos alguns conceitos sociológicos, antropológicos, psicológicos e epidemiológicos, o que caracterizou, nos anos de 1970, a expressão de Medicina Comunitária. Além de vários outros movimentos, os entrevistados citaram o Relatório da Cinaem que expressava resultados da avaliação do ensino médico no Brasil (19911997). Os indicadores dessa avaliação foram reconhecidos e mobilizaram instituições a pactuarem a transformação do ensino médico brasileiro, com vistas a um novo paradigma de formação para a escola médica.

Os entrevistados das duas escolas médicas citam, ainda, várias políticas ministeriais brasileiras, implementadas a partir dos anos 2000, com o propósito de promover mudanças na formação dos profissionais da saúde, tais como:

a) DCN - Diretrizes Curriculares Nacionais da Graduação, instituída em 2001.

b) PROMED - Programa de Incentivo às Mudanças Curriculares nos Cursos de Medicina, proposto pelo Ministério da Saúde, em parceria com o Ministério da Educação em 2002.

c) PORTARIA 198/2004, que instituía a Política de Educação Permanente para o SUS.

d) FNEPAS - Fórum Nacional de Educação das Profissões na Área de Saúde, criado em julho de 2004 .

e) PRÓ-SAÚDE- Programa Nacional de Reorientação da Formação Profissional em Saúde, lançado em novembro de 2005.

f) PET-Saúde- Programa de Educação pelo Trabalho para a Saúde, instituído em 2007.

Compreende-se que as Políticas Nacionais de formação dos profissionais dos cursos da área da saúde reiteram a importância das mudanças na Educação Superior para a consolidação das transformações necessárias; e revelam que podem contribuir significativamente no direcionamento e na reorientação da formação dos profissionais, por meio de incentivos de mudanças curriculares que visam a um novo perfil profissional. 
Nas escolas pesquisadas, essas políticas tiveram impacto significativo no processo de construção dos currículos integrados, em especial no curso de medicina da Unochapecó, implantado em 2006, num contexto normativo, em que se discutiam fortemente as Diretrizes Curriculares Nacionais. No curso de medicina da UFSC, a influência fundamental foi o Programa de Incentivo às Mudanças Curriculares nos Cursos de Medicina, que propiciou o recebimento de recursos financeiros para produção de materiais, bem como a contratação de consultorias pedagógicas para a formação dos docentes envolvidos no processo de reforma curricular do curso.

É possível considerar que, nesse contexto, o Discurso Pedagógico Oficial, por meio de suas políticas, exerce influência nos processos de mudanças curriculares. Entretanto, a formação dos futuros profissionais não se resume apenas a um processo regulatório, exigindo articulações políticas nos segmentos internos e externos às instituições de Educação Superior. Implica, essencialmente, nas relações entre os elementos do tripé: academia, serviços de saúde e necessidades sociais.

\section{A recontextualização do currículo integrado no campo pedagógico}

Para que fosse possível compreender o campo de Recontextualização Pedagógi$c a$, além das entrevistas realizadas, foram analisados os projetos pedagógicos dos dois cursos de medicina a partir dos documentos: Unochapecó (2005) e Pereima, Coelho e Da Ros (2005). Para a análise, foram identificados os seguintes elementos constitutivos: a) concepções filosóficas e teórico-metodológicas; b) perfil profissional; c) concepções de currículo e desenho da matriz curricular.

Embora as duas escolas médicas tenham identidades históricas muito distintas, observa-se que nas produções dos projetos há diversas semelhanças. As duas propostas pedagógicas ressaltam a importância de um novo perfil profissional, fundamentada nas Diretrizes Curriculares Nacionais, ou seja, uma formação generalista, humanística, crítica e reflexiva. Mas recontextualizam esse perfil, trazendo outras características fundamentais relacionadas à ética profissional e à criticidade das práticas, assim como enfatizando a visão mais integrada do ser humano, o raciocínio clínico na resolutividade de problemas, melhor performance diagnóstica e terapêutica, entre outras características identificadas no decorrer dessa pesquisa.

Em relação à concepção de currículo, o desafio foi ultrapassar a visão disciplinar e fragmentada do conhecimento e também a visão restrita do ser humano biológico. 
Com essa concepção, ambas as escolas propõem a integração curricular a partir da estruturação de módulos temáticos, seguindo uma espiral ascendente, sendo a Interação Comunitária o eixo central da integração no currículo. Os conteúdos de ensino abordados foram categorizados de acordo com o referencial teórico de Zabala (2002), em que o autor classifica os conteúdos em cognitivos, procedimentais e atitudinais. Dessa forma, as propostas curriculares possibilitam a integração teoria e prática, objetivando integrar o saber-fazer em diversos cenários de prática, ampliando sua capacidade de inserção no campo social desde as primeiras fases do curso.

Assim, ao enfatizar a integração das áreas de conhecimentos, os sujeitos envolvidos na construção da proposta recontextualizam a representação do currículo, fazendo uso de desenhos para expressar a organização curricular, diferenciando-a das tradicionais grades curriculares tão conhecidas nas instituições de Ensino Superior brasileiro.

Em relação aos fundamentos teóricos-metodológicos da proposta do currículo integrado, são visualizados os princípios relacionados ao paradigma da integralidade que se expressam nas diferentes políticas de saúde, assim como em diversas conferências mundiais e nacionais realizadas ao longo da história.

Já no contexto da prática pedagógica, as duas propostas incentivam o desenvolvimento de metodologias ativas com o objetivo de tornar o processo ensino-aprendizagem ainda mais significativo na formação do acadêmico. Consequentemente também defendem uma concepção de avaliação formativa, ou seja, um olhar avaliativo para o processo dessa aprendizagem.

Diante desses desafios pedagógicos, percebe-se que as práticas pedagógicas dos professores médicos ainda não são condizentes com o modelo curricular proposto. Na percepção dos entrevistados, a profissionalização docente seria uma das alternativas à consolidação dessas práticas pedagógicas inovadoras.

Foi diagnosticado que, no processo da discussão da proposta, a participação dos docentes ficou aquém do esperado. Apesar do investimento financeiro, das chamadas para formações pedagógicas, das reuniões nas instâncias internas e dos seminários, a participação docente foi insuficiente.

Identificou-se, ainda, que as construções dos textos das propostas curriculares apresentadas foram delineadas e ressignificadas por diversos olhares e vozes. Algumas vozes mais presentes do que outras. Assim como as resistências e os conflitos foram evidenciados, gerados pela nova proposta curricular, em detrimento da própria história, da cultura da formação médica e da visão de ensino. Segundo Cutolo 
(2001), os estilos de pensamento que predominam nos docentes de medicina são o estilo organicista e o biologicista com marcada influência na prática curricular, o que caracteriza as resistências e as dificuldades de compreender uma proposta curricular integrada, com ênfase no ser humano biopsicossocial.

É dado apoio à teoria do Dispositivo Pedagógico de Bernstein (1996), quando esse explicita que os meios discursivos estabelecem suas próprias representações e sua identidade social. Para Lopes e Macedo (2011),

a recontextualização, como processo social, não é desenvolvida por uma pessoa, o professor, por exemplo. Existe um contexto recontextualizador que reposiciona e refocaliza os diferentes textos sociais produzidos. Na recontextualização, os diferentes textos são simplificados, condensados e reelaborados. Partes são aproveitadas, outras são desconsideradas, releituras são feitas e ideias inicialmente propostas são inseridas em contextos outros, que permitem sua ressignificação (p. 104).

Assim, os textos das propostas curriculares analisadas difundem códigos de sua organização, constituídos de culturas, princípios e práticas pedagógicas. Entretanto, a produção do currículo não é a realidade dos efeitos convertidos em significados aprendidos, pois "toda proposta de texto é traduzida pelos leitores. Ao interpretá-la, pode ser enriquecida e até subvertidas as suas intenções” (Gimeno Sacristán, 2007, p.118).

\section{Considerações}

Compreende-se que as perguntas iniciais desta pesquisa se entrelaçam com outras reflexões que emergiram no decorrer do diálogo com os entrevistados. Na percepção dos atores sociais, o contexto da mudança nos cursos de medicina se inscreve num movimento histórico, na consolidação de um novo modelo de saúde, o que representa uma projeção de outro perfil profissional que supere a formação biomédica motivada pelas influências do complexo médico industrial. Portanto observa-se que, nas duas propostas, as mudanças estão atreladas a um objetivo comum: um novo perfil de formação médica.

No que concerne aos aspectos pedagógicos e curriculares, as mudanças se inserem na superação da lógica da organização do conhecimento compartimentado e descontextualizado, numa perspectiva de currículo que visa integrar o conhecimento, articulando teoria, prática e contexto social. 
Foi possível constatar que as propostas de mudanças curriculares nascem das influências internacionais, dos movimentos sociais da área de saúde, das políticas nacionais indutoras de mudanças, assim como das políticas locais, e por meio de outros contextos. Entretanto, observa-se que as escolas médicas analisadas, ao produzirem seus planos curriculares à luz das políticas e das manifestações de mudanças, não as reproduziram mecanicamente, mas as recontextualizaram, criaram alternativas próprias e peculiares de acordo com sua realidade institucional e perfil de docentes. As políticas curriculares são recontextualizadas pelos sujeitos sociais, e essa recontextualização, no sentido de Bernstein, produz diferentes discursos pedagógicos.

Da mesma forma, ao programarem o currículo proposto, compreendem que, ao ser executado, novas formas e sentidos foram concebidos pelos sujeitos sociais envolvidos. Nos dizeres de Pacheco (2000), ao questionar o currículo como prática, admitem-se possibilidades de uma lógica de desconstrução, ou seja, definir o que se pretende - intenções curriculares, e o que efetivamente ocorre - realidade curricular.

Para compreender essas fronteiras oriundas das reformas e das inovações curriculares, é preciso desvelar os discursos e as razões nos quais se baseiam esses novos sentidos, como também as resistências e as mudanças que geram conflitos e impedimentos no desenrolar desse processo.

Por fim, dentre os desafios apontados, há avanços relevantes perceptíveis nas propostas de currículos integrados, dos quais se destacam: organização curricular: modular e espiral; indissociabilidade entre teoria, prática e realidade social; ações pedagógicas integrativas; visão do cuidado integral do ser humano; inserção do acadêmico na comunidade.

Espera-se que esta pesquisa, ao analisar duas experiências curriculares, possa ter proporcionado algumas reflexões e contribuições para futuras propostas que visam construir currículos integrados. Compreende-se que cada proposta, ao ser idealizada, construída e implementada, será recontextualizada por seus atores sociais, como cidadãos construtores dessa história, a partir de seus sentidos e significados. Acredita-se, ainda, que essas propostas curriculares possam contribuir na formação profissional com base nos saberes essenciais da formação médica, mas, essencialmente, na compreensão do ser humano nas suas dimensões do ser. 


\section{Referências bibliográficas}

Bernstein, B. B. (1981). Codes, modalities and the process of cultural reproduction: a model. Language and Society, 10, 327-363.

Bernstein, B. B. (1996). A estruturação do discurso pedagógico: classe, códigos e controle. Petrópolis: Vozes.

Bernstein, B. B. (2003). A pedagogização do conhecimento: estudos sobre recontextualização. Cadernos de Pesquisa [on-line], 120, 75-110.

Bourdieu, P. (2000). As regras da arte. São Paulo: Cia. das Letras.

Cutolo, L. R. A. (2001). Estilo de pensamento em educação médica: um estudo do currículo do curso de graduação em medicina da UFSC. 227f. Tese de Doutorado em Educação, Centro de Ciências da Educação, Universidade Federal de Santa Catarina, Florianópolis.

Feuerwerker, L. C. M. (2002). Mudanças na educação médica: os casos de Londrina e Marília. Tese de Doutorado em Prática de Saúde Pública, USP, São Paulo.

Gimeno Sacristán, J. (2007). A Educação que ainda é possível: ensaios sobre uma cultura para a educação. Porto Alegre: Artmed.

Goodson, I. F. (1995). Currículo: teoria e história. Petrópolis: Vozes.

Lopes, A. C. (1999). Conhecimento escolar: ciência e cotidiano. Rio de Janeiro: UERJ.

Lopes, A. C. (2008). Políticas de integração curricular. Rio de Janeiro: UERJ.

Lopes, A. C., \& Macedo, E. (2011). Teorias de currículo. São Paulo: Cortez.

Mainardes, J., \& Stremel, S. (2010, maio/agosto). A teoria de Basil Bernstein e algumas de suas contribuições para as pesquisas sobre políticas educacionais e curriculares. Revista Teias, 11(22), 1-24.

Pacheco, J. A. (Org). (2000). Políticas de integração curricular. Porto, Portugal: Porto Editora

Pereima, M. J. L., Coelho, E. B. S., \& Da Ros, M. A. (Orgs.). (2005). Da proposta à ação: currículo integrado do curso de graduação em Medicina da UFSC. Florianópolis, SC: UFSC.

Perim, G. L. (2007). Avaliação da educação superior: uma realidade na educação mé dica. 363 fs. Tese de Doutorado em Educação, Unicamp, Campinas, SP.

Torres Santomé, J. (1998). Globalização e interdisciplinaridade: o currículo integrado. Porto Alegre: Artes Médicas Sul. 
Unochapecó. Universidade Comunitária Regional de Chapecó - Reitoria. (2005). Cen tro de Ciências da Saúde. Curso de graduação em medicina. Síntese do Projeto do curso de graduação em medicina com respectivo projeto político pedagógico, Chapecó.

Zabala, A. (2002). Enfoque globalizador e pensamento complexo: uma proposta para o currículo escolar. Porto Alegre: ArtMed.

Submetido à avaliação em 25 de outubro de 2014; aprovado para publicação em 30 de janeiro de 2015. 